\title{
Highly-sensitive Biosensors with Chemically-amplified Responses
}

\author{
Fumio Mizutani, ${ }^{\text {* }}$ Dai Kato, ${ }^{\mathrm{b}}$ Ryoji Kurita, ${ }^{\mathrm{b}}$ Yasuhiro Mie, ${ }^{\mathrm{c}}$ Yukari Sato, ${ }^{\mathrm{b}}$ \\ and Osamu Niwa ${ }^{\text {b }}$
}

\begin{abstract}
a Graduate School of Material Science, University of Hyogo (3-2-1 Kouto, Kamigori, Ako-gun, Hyogo 678-1297, Japan) ${ }^{\text {b}}$ Tsukuba Center, National Institute of Advanced Industrial Science and Technology (AIST) (1-1-1 Higashi, Tsukuba, Ibaraki 305-8566, Japan)

'Hokkaido Center, National Institute of Advanced Industrial Science and Technology (AIST) (2-17-2-1 TsukisamuHigashi, Toyohira-ku, Sapporo, Hokkaido 062-8517, Japan)
\end{abstract}

Received February 27, 2008 ; Accepted June 16, 2008

\begin{abstract}
This article describes the development of biosensors with chemically-amplified responses. In general, chemical amplification involves a reaction sequence for a substance to generate a relatively large amount of product. Thus a trace concentration of analyte can be caused to yield orders of magnitude higher product concentrations which may be more easily measured than the analyte itself. For biosensor systems to detect biochemical reactions on the transducer surfaces, chemical amplification procedures suitable for concentrating the reaction product on the transducer/test solution interface should be utilized to enhance the sensor response effectively. The amplification procedures, such as enzymatic cycling at the enzyme-modified electrode and the preconcentration of the biochemical reaction product on the electrode surface, are particularly useful for realizing highly-sensitive biosensors. The combination of such amplification techniques with immunoassay protocols has provided simple measuring systems for trace amounts of peptide hormones, such as A- and B-type natriuretic peptides and insulin. These simple and highly-sensitive immunoassay systems are suitable for the purpose of the point-of-care testing.
\end{abstract}

Key Words : Biosensor, Chemical Amplification, Enzymatic Cycling, Surface Accumulation, Peptide Hormones, Pointof-Care Testing

\section{Introduction}

Analytical devices combining the high specificity of biolochemical reaction with the simplicity of electrochemical signal transduction have attracted increasing interest in the last three decades. Particular effort in this field has been directed to the fabrication of blood glucose sensors. The sensor market for the self-monitoring of blood glucose (SMBG) is expected to be 1 trillion yen in the world in 2011. ${ }^{1)}$ The wide spread of the sensors for SMBG has clearly demonstrated the usefulness and importance of biosensor technologies, and stimulated us to realize sensors for the point-of-care testing (POCT) of different components in biological samples to diagnose a variety of diseases. Especially, POCT systems for the simple and rapid diagnosis of severe diseases such as cancers and heart failures are desired. For example, there are 1 million Japanese (and 5 million American) with severe congestive heart failure (CHF), and the determination of a cardiac neurohormone, B-type natriuretic peptide (BNP), provides useful information for the diagnosis of CHF. ${ }^{2,3)}$ However, the concentrations of markers for these diseases are usually extremely low. Figure 1 shows the concentrations of typical blood components: the normal blood BNP concentrations are picomolar levels.

The detection limit is, of course, determined by the signal/noise-ratios for measuring the analyte. The POCT systems must be simple, small and inexpensive. Therefore biosensors, as well as immunochromatgraphic plates, seem to be very useful as the sensing devices of POCT systems. However, in such simple sensing systems, the sufficient noise reduction is usually difficult, which brings about a rather high limit of detection. Figure 1 also shows the analyte concentration ranges that can be measured by using conventional biosensors and immunochromatographic plates. The detection limits given by these devices are much higher than picomolar levels: it is impossible to determine BNP (and other markers such as ANP and insulin) by employing such conventional, simple apparatus. Therefore, methods for enhancing signal output is required, so that one can fabricate simple POCT systems to measure extremely low concentration of analytes.

For increasing the signal levels, chemical amplification is a highly suitable methodology. In general, chemical amplification consists of a reacting a substance to generate a relatively large amount of product. Hence a trace concentration of analyte can be caused to yield orders of magnitude higher product concentrations which may be more easily measured than the analyte itself. ${ }^{4)}$ For biosensor systems to detect biochemical reactions on the transducer surfaces, chemical amplification procedures suitable for concentrating the product on the transducer/test solution interface should be utilized to enhance the sensor response effectively. The amplification procedures, such as enzymatic cycling at the enzyme-modified electrode $^{5,6)}$ and the preconcentration of the biochemical reaction product on the electrode surface, ${ }^{7,8)}$ are particu- 


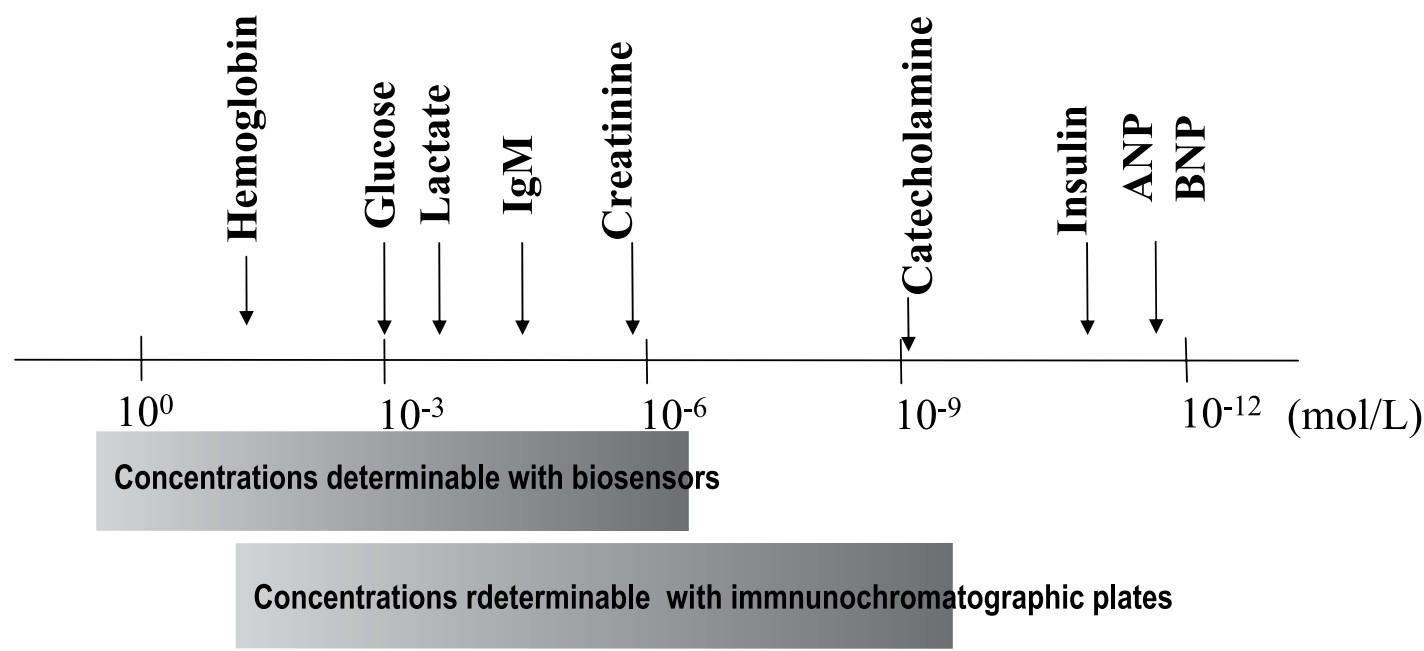

Fig. 1 The concentrations of typical components in blood and the measurable concentration ranges by using conventional biosensors and immunochromatographic plates.

larly useful for realizing highly-sensitive biosensors. Actually, we have successfully determined A-type of natriuretic peptide (ANP), a marker for heart and kidney diseases, at picomolar levels by utilizing cyclic reactions at an enzyme-modified electrode, ${ }^{9)}$ and BNP at the same concentration levels based on a preconcentration/detection procedure. ${ }^{10)}$ This article describes progress of biosensing systems with chemically amplified responses for providing simple and highly-sensitive assay systems that are compatible with the POCT technologies.

\section{Enzymatic Cycling}

\section{1 Cycling reactions using a couple of enzymes}

An interesting approach for achieving amplification is through a reaction sequence that casts the analyte into a cycling role to cause a relatively large concentration change of measurable species:

$$
\begin{aligned}
& \text { enzyme } 1 \quad \text { enzyme } 2 \\
& \mathrm{~S}+\mathrm{R}_{1} \rightarrow \mathrm{P}+\mathrm{P}_{1} ; \mathrm{P}+\mathrm{R}_{2} \rightarrow \mathrm{S}+\mathrm{P}_{2}
\end{aligned}
$$

If only enzyme 1 is used for the determination of the substrate $S$, the concentration change of the reactant $R_{1}$ or the product $P_{1}$ is stoichiometrically limited by the concentration of S. On the other hand, the additional use of the enzyme 2 permits the enhanced concentration change of $R_{1}$ or $P_{1}$ beyond the stoichiometric limitation. The increased concentration change provides an inherent gain in sensitivity for measuring S. In 1960s, Lowry et $a l .{ }^{11)}$ have reported the determination of cofactors at concentrations of $10^{-9}-10^{-13} \mathrm{M}$ by measuring the product accumulated through the enzymatic cycling reactions. $\mathrm{We}^{12-17)}$ and Scheller et al. ${ }^{18-21)}$ have successfully applied the cycling principle to the construction of highly-sensitive enzyme sensors. For example, an L-lactatesensing electrode with the detection limit of $1 \mathrm{nM}$ could be prepared by using an oxygen electrode equipped with a bi-enzyme layer containing lactate oxidase to oxidize the analyte with the consumption of oxygen and lactate dehydrogenase (LDH) to regenerate the analyte. ${ }^{12,13)}$
The signal for $L$-lactic acid was amplified $c a$. 200 times by introducing the LDH-catalyzed regeneration of the analyte. ${ }^{13)}$

\section{2 Cycling reactions using a single enzyme}

The high selectivity of enzyme is useful for undergoing the analyte into the cycling reaction sequence without the loss by the side reactions. If a chemical reaction proceeds with adequate selectivity, it can be introduced to replace the corresponding enzymatic reaction. Uchiyama et $a .^{22)}$ have prepared a sensor for $L$-ascorbic acid with an amplified response (amplification factor, $c a$. 20) by coupling the chemical regeneration of the analyte by using a reducing reagent, dithiothreitol, with an ascorbate oxidase-catalyzed reaction. They ${ }^{23)}$ have obtained an amplification factor of $>100$ for a uricate sensor based on the uricase-catalyzed reaction and the analyte regeneration with dithiothreitol.

The use of an electrochemical reaction, instead of the chemical reaction, can provide a single enzyme-based electrode exhibiting an enhanced electrode response without the addition of a reducing (or oxidizing) reagent. $\mathrm{We}^{6)}$ have determined catechols by using a glucose oxidase (GOD)-modified electrode:

$$
\begin{aligned}
& \text { catechol } \rightarrow o \text {-quinone }+2 \mathrm{H}^{+}+2 \mathrm{e} \text { (at the electrode) } \\
& o \text {-quinone }+ \text { glucose } \rightarrow \text { catechol }+ \text { gluconolactone (in } \\
& \text { the GOD layer) }
\end{aligned}
$$

The regeneration of the analyte by the GOD-catalyzed reaction provided an amplified response (amplification factor, 60) for catechol (and dopamine). The detection limit of catechol (and dopamine) was $c a .1 \mathrm{nM}$.

For the determination of dopamine in biological samples, there was a serious problem with interference from oxidizable species, such as L-ascorbic acid and uric acid, coexisted in the samples. This could be solved by performing the cyclic electrochemical/GOD-catalyzed-reactions in a rapid coulometric cell ${ }^{24,25)}$ using a porous carbon felt electrode impregnated with a GOD-containing electrolytic solution. When a small volume of sample was 
dropped onto the carbon felt electrode surface, the sample diffused into the porous carbon felt to undergo the electrode reaction. The current for oxidizing interferants were diminished within $1 \mathrm{~min}$ because they were consumed through the electrochemical reactions. On the other hand, the current for oxidizing dopamine in the same sample remained unchanged owing to the regeneration by GOD. From the steady-state current obtained 1 min after the addition of the sample, the dopamine concentration from 5 to $500 \mathrm{nM}$ could exactly be determined even when relatively high concentration $(>1 \mu \mathrm{M})$ of L-ascorbic acid (and uric acid) was coexisted. ${ }^{26,27)}$

The amplification of electrolytic current with cycling reactions can, of course, be achieved by employing chemical reaction/electrochemical reaction-sequences ${ }^{28)}$ or redox reactions on a couple of electrodes. ${ }^{29)}$ Especially, redox cycling using interdigitated array microelectrodes has widely been applied for the construction of highlysensitive sensor systems, involving immunoassay systems. ${ }^{30)}$

2. 3 The application of enzyme cycling technique to various biosensing systems

The determination of various biomolecules could be carried out by applying the cyclic electrochemical/enzymatic-reaction-based system. A peptide hormone, ANP, was determined by combining a competitive immunoassay technique using alkaline phosphatase-labeled antiANP antibody (ALP-Ab) with the sensitive determination of the enzyme activity on a GOD-modified electrode, as illustrated in Fig. 2.9) A certain amount of ANP sample was added to a solution containing ALP-Ab to undergo immunological reactions. Then an ANP-modified gold disc was inserted to the immuno-reaction mixture in order to have unreacted ALP-Ab attached onto the ANP-modified gold surface. The gold disc with bound ALP-Ab was soaked in a $p$-aminophenylphosphate (PAPP) solution to generate $p$-aminophenol (PAP) through the enzymatic reaction. PAP was oxidized on the GOD-modified electrode surface but regenerated through the enzymatic reaction in the presence of glucose to improve the sensitivity for PAP. This enabled us

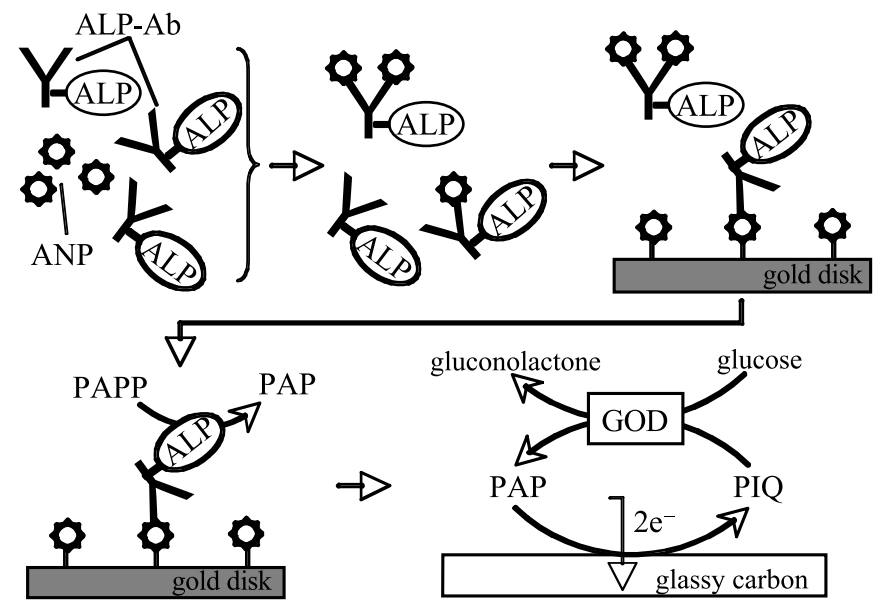

Fig. 2 Procedure for the measurement of ANP with the use of electrochemical/enzymatic-cycling reactions (Ref. 9). to detect the slight change in the enzyme activity (i.e., amount) of ALP-Ab attached on the ANP-modified disc and, therefore, measure a tiny amount of ANP in the sample. The detection limit of ANP, $1.5 \mathrm{pM}(5 \mathrm{pg} / \mathrm{mL})$, was low enough for the determination of blood ANP levels, although some improvement was required to shorten the measuring time.

Another type of the application of the electrochemical/enzymatic-cycling system was the detection of DNA. The sensitive, on-site determination of DNA is necessary for monitoring biopharmaceutical production processes using continuous cell lines. The intravenous administration of the cellular products contaminated with their oncogenes in the residual host cell may cause the cellular transformation of the oncogenic DNA. Thus the cellular DNA content in the product is recommended to be $<10 \mathrm{ng} / \mathrm{mL}^{31)}$ A redox-active intercalator, methylene blue (MB), has been employed for the measurement of DNA with a peroxidase (HRP)-modified electrode. ${ }^{32)} \mathrm{MB}$ is reduced on the electrode, and reoxidized by HRP-catalyzed reaction in the presence of hydrogen peroxide. The current response for MB was remarkably reduced in association with its complexation with DNA: the steric hindrance of $\mathrm{MB}$ in the complexes (as well as the lowering of the diffusion coefficient of MB after the complexation) brought about the decreases in both the electron transfer and enzymatic reaction rates. The amplification of the electrode response of MB by the regeneration with HRP (amplification factor, 45) resulted in the highlysensitive measurement of the electrochemical and enzymatic activity change of $\mathrm{MB}$ by the complexation with DNA, and, therefore, in that of the DNA concentration. The detection limit of DNA (from salmon testes) obtained, $10 \mathrm{ng} / \mathrm{mL}^{32}$ was lower than that given by using stripping analysis methods. ${ }^{33,34)}$

The similar methodology could be applied to the detection of lipopolysaccharide (LPS) by using a ferroceneboronic acid derivative $(\mathrm{FcB})^{35)}$ as a reagent to

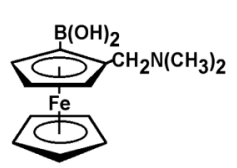

ferrocenylboronic acid derivative (FcB)

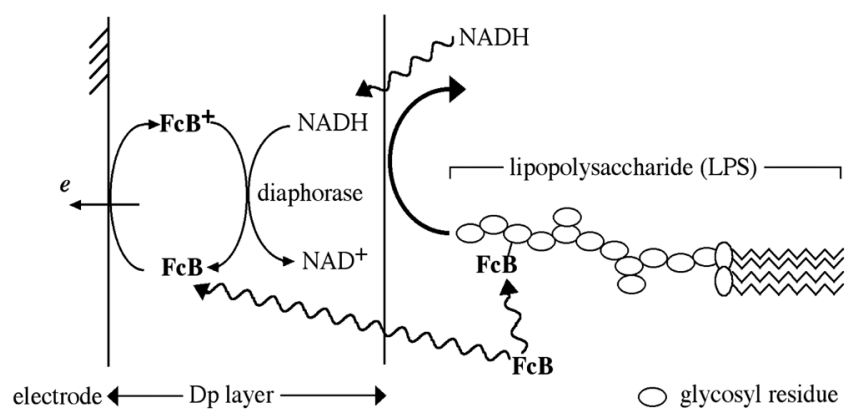

Fig. 3 The chemical structure of ferrocenylboronic acid derivative $(\mathbf{F} \mathbf{c B})$ and a schematic illustration of the measurement using a combination of $\mathbf{F} \mathbf{c B}$ and an enzymemodified electrode (Ref. 35). 
recognize LPS. LPS, a major component of the outer membrane of Gram-negative bacteria, is known as endotoxin that triggers a wide variety of biological effects such as septic shock and coagulopathies in humans. FcB attached to glycosyl units of LPS so that the current response at a diaphorase (Dp)-modified electrode was remarkably reduced owing to the decrease in the rate of the electrochemical oxidation of the ferrocene derivative as well as that of the Dp-catalyzed regeneration, as illustrated in Fig. 3. From the current decrease at the Dpmodified electrode, LPS was detected with high sensitivity: the detection limit of the LPS from Escherichia coli O127:B8 was as low as $50 \mathrm{ng} / \mathrm{mL}$. ${ }^{36)}$

\section{Accumulation of the Enzymatic Reaction Product}

\section{1 Accumulation of thiol on metal electrode surface}

When a substrate is readily accumulated on the surface of electrode, and also when the substrate accumulated is easily detected electrochemically, it can be measured with enhanced sensitivity on the electrode. Thiols (RSH) is chemisorbed on metal (M) electrodes and the thiolate ( $\mathrm{RS}^{-}$) chemisorbed is desorbed through one-electron path. ${ }^{37)}$

$$
\begin{gathered}
\mathrm{RSH}+\mathrm{M} \rightarrow \mathrm{RS}-\mathrm{M}+1 / 2 \mathrm{H}_{2} \\
\mathrm{RS}-\mathrm{M}+\mathrm{e} \rightarrow \mathrm{RS}^{-}+\mathrm{M}
\end{gathered}
$$

The chemisorption (accumulation)/desorption (detection)-process can be applied to the highly-sensitive determination of thiols and thiol-producing enzymes (Fig. 4). We have determined 6-mercaputopurin, ${ }^{8)}$ a drug of antimetabolite, and acetylcholinesterase $(\mathrm{AChE})^{7,38}$ that produced thiocholine through the hydrolysis of acetylthiocholine, with the detection limits of $10 \mathrm{nM}$ and 10 $\mathrm{mU} / \mathrm{L}$, respectively. The chemisorption/desorption-procedure for measuring the AChE activity has successfully been combined with immunoassay systems by using $\mathrm{AChE}$ as a marker enzyme. ${ }^{10,39)} \mathrm{By}$ combining a competitive immunoassay protocol with the accumulation-based AChE-determination technique, BNP from 15 to $150 \mathrm{pM}$ could be determined within an hour. ${ }^{10}$

More sensitive and rapid determination of BNP has been achieved by the combination of the accumulationbased assay procedure with a microfluidic system (Fig. 5). ${ }^{40)}$ In general, (bio-)chemical reactions including chemisorption proceed quickly in a miniaturized system, since a small diffusion length in the system provides the increase in the number of collision between molecules (and collision of an adsorbate against the transducer surface). Furthermore, the ratio of the transducer surface area to the sample volume readily increases in association with the miniaturization of the measuring system: if one miniaturize a measuring cell equipped with a transducer to be $1 / N$ of the original size, the transducer surface area-to-sample volume ratio increases by a factor of $N$. These can enhance the efficiency of the (bio-)chemical reaction process, especially in the surface accumulation process, which result in much improved sensitivity of the accumulation-based assay. ${ }^{41,42)}$ Actually, BNP as low as $1.5 \mathrm{pM}$ could be detected within $30 \mathrm{~min}$, by using a microfluidic device. ${ }^{40)}$ A surface plasmon resonance (SPR) sensor has been proved to be useful for monitoring the thiocholine accumulated on the sensor surface with high sensitivity. ${ }^{40)}$ Of course, such an on-chip immunoassay system is highly compatible with POCT.

The thiocholine-based AChE-assay system was also applied to the detection of organophosphorus pesticides. ${ }^{43,44)}$ The inhibition of AChE activity by organophosphorus pesticides was monitored from the decrease of the desorption current of thiocholine. Diazinon from 30 to $150 \mathrm{nM}(10-50 \mathrm{ng} / \mathrm{mL})$ and ethylthiometon from 35 to $700 \mathrm{nM}(10-200 \mathrm{ng} / \mathrm{mL})$ has been determined.

3.2 Accumulation of $\left[\mathrm{Os}(\mathrm{bpy})_{2}\right]^{3+}$ on enzyme/polymercoated electrode

The activity of cholinesterase (ChE; acylcholine acylhydrolase), which also catalyzes the hydrolysis of acetylthiocholine, in serum sample is very high ( $c a .4000$ $\mathrm{U} / \mathrm{L}$ ). This means that the nonspecific adsorption of serum $\mathrm{ChE}$ in the thiocholine-based assay device may produce excessive thiocholine moieties from acetylchioline to cause a serious error for measuring the analyte. Therefore, we have used a heat-inactivated serum as the sample for the exact determination of BNP. ${ }^{40)}$

The use of an enzyme, whose activity in the sample is

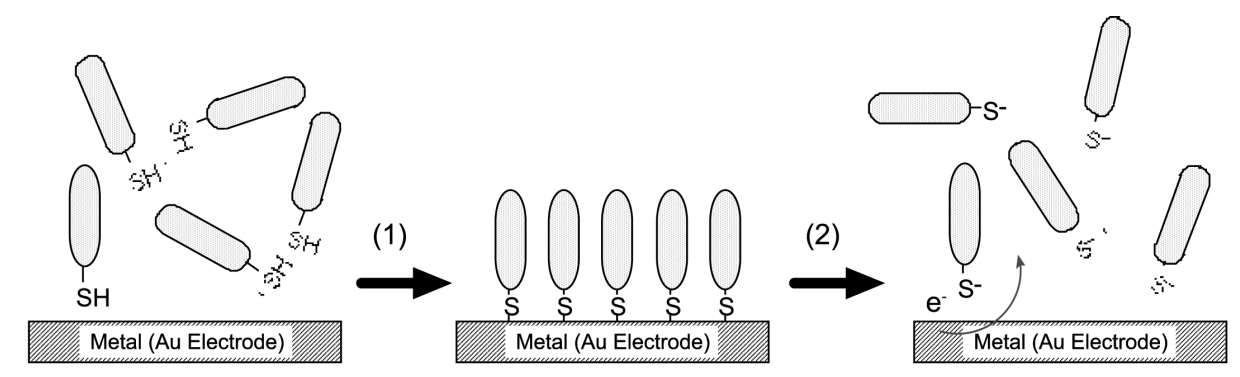

SSH

\section{Thiol Chemisorption (accumulation) \\ Electrochemical Desorption}

Fig. 4 Schematic illustration for the chemisortption (accumulation) and electrochemical desorption (measurement) of thiol compound on a metal (gold) electrode (Ref. 8). 
(a)

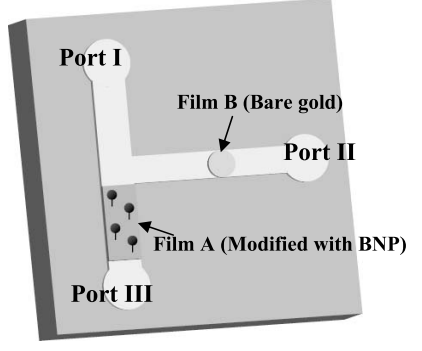

(b)

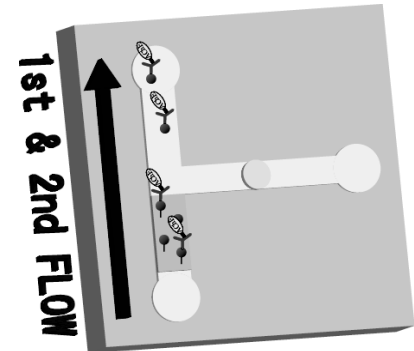

(c)

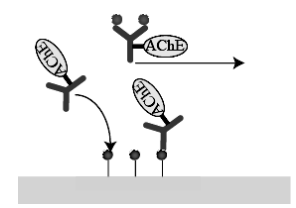

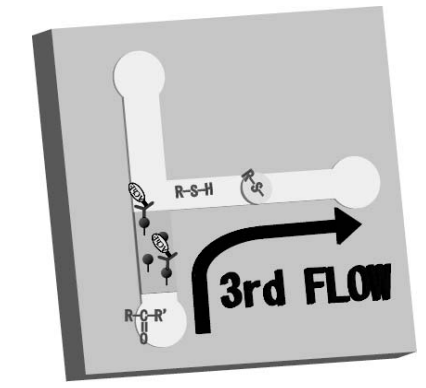

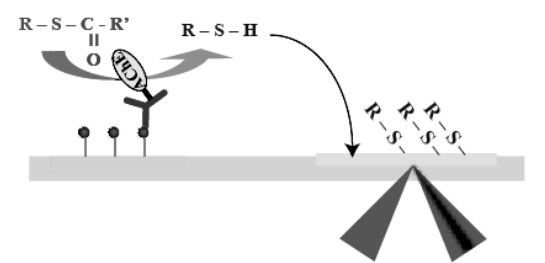

Fig. 5 Schematic diagram of the procedure for BNP determination in the micro-immunosensor. (a) Structure of the immunosensor. Film A is modified with BNP for the collection of unreacted anti-BNP antibody modified with AChE. Film B is a bare gold film for the detection of the thiocholine accumulated. (b) Introduction of a mixture solution containing BNP and anti-BNP antibody modified with AChE from port III to port I. The unreacted antibody was collected on the film A during the first flow. Then the channel was rinsed with a phosphate buffer during the second flow. (c) Acetylthiocholine was introduced from Port III to Port II. Thiocholine was produced from acetylthiocholine by the collected anti-BNP antibody modified with AChE on Film A, then the product was accumulated on film B and was monitored by the SPR angle shift during the third flow (Ref. 39).

zero or extremely low, as a modifier for antibody is a suitable approach to avoiding such a troublesome sample pretreatment. GOD seems to be a useful as a modifier: GOD is not contained in human blood and urine samples, and shows high stability and specific activity. We have developed a simple and sensitive method for measuring the GOD activity. ${ }^{45)}$

Poly(vinylpyridine) containing $\left[\mathrm{Os}(\mathrm{bpy})_{2}\right]^{2+}$ and HRP (Os ${ }^{\mathrm{II}} / \mathrm{HRP}$-polymer) has widely been used for the amperometric determination of hydrogen peroxide in the concentration range from 0.1 to $100 \mu \mathrm{M}^{46,47)}$ Iwasaki et al. ${ }^{48)}$ have applied the OsII/HRP-polymer to the detection of oxidase-catalyzed reactions with a SPR sensor system: $\left[\mathrm{Os}(\mathrm{bpy})_{2}\right]^{2+}$ in the polymer was oxidized by hydrogen peroxide to produce $\left[\mathrm{Os}(\mathrm{bpy})_{2}\right]^{3+}$, which followed the transport of anion from the solution to the polymer layer. The anion accumulated was detected by the layerattached SPR sensor. The SPR-based system is of interest because it can provide the real time visualization of concentration distribution for enzymatically-produced hydrogen peroxide. ${ }^{49)}$ However, the sensitivity for hydrogen peroxide was low (detection limit, $0.1 \mathrm{mM}$ ) owing to the small change in the refractive index of the polymer upon the accumulation of anionic species.

On the other hand, the accumulation process is inherently advantageous for increasing the sensitivity. Instead of the SPR measurement, a coulometric method was employed for determining the $\left[\mathrm{Os}(\mathrm{bpy})_{2}\right]^{3+}$ accumulated (Fig. 6), i.e., an Os ${ }^{\mathrm{II}} / \mathrm{HRP}$-polymer-coated electrode is immersed in a test solution containing GOD and glucose for 10 min under the open circuit condition, then the reduction of the $\left[\mathrm{Os}(\mathrm{bpy})_{2}\right]^{3+}$ accumulated in the
GOD/glucose solution was conducted by applying the potential of $-0.1 \mathrm{~V}$ vs. $\mathrm{Ag} / \mathrm{AgCl}$. The charge for the reduction of $\left[\mathrm{Os}(\mathrm{bpy})_{2}\right]^{3+}$ was proportional to the GOD activity up to $40 \mathrm{mU} / \mathrm{L}$. The detection limit for GOD was $0.1 \mathrm{mU} / \mathrm{L}$ (the detection limit for hydrogen peroxide, $<1$ nM). ${ }^{45)}$ Our preliminary experiments have shown that insulin in the range from $2 \mathrm{pM}(10 \mathrm{pg} / \mathrm{mL})$ to $10 \mathrm{nM}(50$ $\mathrm{ng} / \mathrm{mL}$ ) could be detected by employing a GOD-labeled immunoassay system coupled with the above $\left[\mathrm{Os}(\mathrm{bpy})_{2}\right]^{3+}$-accumulation/coulometric-detecting procedure. ${ }^{50)}$ The total assay time was $30 \mathrm{~min}$. The detection limit was low enough for the determination of blood insulin levels.

\section{Conclusions}

The combination of chemical amplification strategies with biosensor technologies have proved to be useful for preparing simple and highly-sensitive biosensor systems involving immunosensor systems.

Most recently, we have developed a simple fluid handling technique, "drop-and-sip" technique, to deliver the sample from a hydrophobic microchannel to hydrophilic sensing chambers. ${ }^{51,52)}$ This method required only a micropipette to deliver the sample solution. However, it is still difficult to apply this method to enzyme immunoassay protocol in which multi-step fluidic transport is usually required as shown in Fig. 5. Further development of simple and reliable techniques for the microfluidic transport and solution mixing is strongly desired for the realization of sensitive microsensor-based POCT systems. Electrochemical techniques may be used not only for the measurement of analyte but also for the 


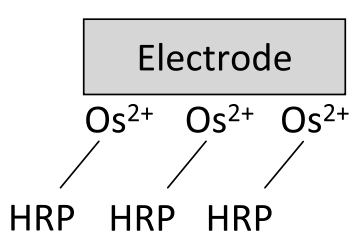

GC electrode coated with Os"/HRP-polymer

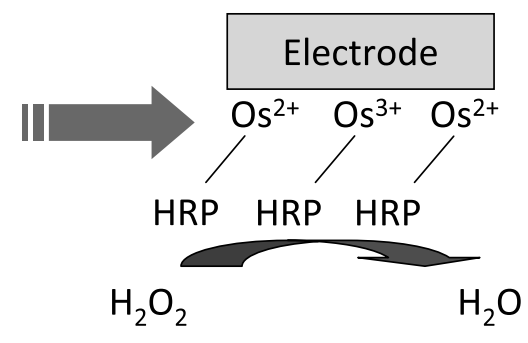

Oxidation of $\left[\mathrm{Os}(\mathrm{bpy})^{2}\right]^{2+}$ under open circuit

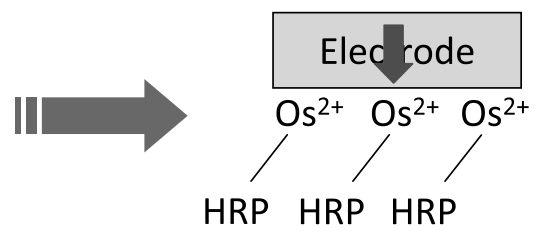

Coulometric measurement (regeneration of $\left[\mathrm{Os}(\mathrm{bpy})^{2}\right]^{2+}$ )

\section{condition (The accumulation of [Os(bpy)2]2+)}

Fig. 6 Schematic procedure for the determination of hydrogen peroxide (or hydrogen peroxide-producing enzyme) with an $\mathrm{Os}^{\mathrm{II}}$ /HRP-polymer-coated electrode (Ref. 42).

microfluidic transport. ${ }^{53,54)}$

On the other hand, recent research trends have demonstrated the importance of biosensing systems based on living cells.55) The introduction of chemical amplification techniques into the living cell-based sensors would be useful for ensuring the safety of our society.

\section{References}

1) T. Ito, in Handbook of Biosensors and Chemical Sensors (Eds. I. Karube, M. Goto, H. Suzuki, I. Taniguchi and K. Yokoyama), Fujitec, Tokyo, p.434 (2007) [in Japanese].

2) Q. Dao, P. Krishnaswamy, R. Kazanegra, A. Harrison, R. Amirnovin, L. Lenert, P. Clopton, J. Allberto, P. Halvin, and A. S. Maisel, J. Am. Coll. Cardiol., 37, 156 (2001).

3) A. S. Maisel, P. Krishnaswamy, R. M. Nowak, J. MacCord, J. E. Hollander, P. Duc, T. Omland, A. B. Storrow, W. T. Abraham, A. H. B. Wu, P. Clopton, P. G. Stef, A. Westheim, C. W. Knudsen, A. Perez, R. Kazanegra, H. C. Herrmann, and P. A. McCullogh, $N$. Engl. J. Med., 347, 161 (2002).

4) W. J. Blaedel and R. C. Boguslaski, Anal. Chem., 50, 1026 (1978).

5) F. Mizutani and M. Asai, in Bioinstrumentation (Ed. D. L. Wise), Butterworths, Boston, p.317 (1990).

6) F. Mizutani, S. Yabuki, and M. Asai, Biosens. Bioelectron., 6, 305 (1991).

7) H. Matsuura, Y. Sato, T. Sawaguchi, and F. Mizutani, Chem. Lett., 2002, 618.

8) Y. Sato, Y. Ishikawa, H. Matsuura, K. Uosaki, F. Mizutani, and O. Niwa, Electroanalysis, 17, 965 (2005).

9) Y. Mie, D. Kato, O. Niwa, and F. Mizutani, Electrochemistry, 74, 138 (2006).

10) H. Matsuura, Y. Sato, O. Niwa, and F. Mizutani, Anal. Chem., 77, 4235 (2005).

11) O. H. Lowry, Acc. Chem. Res., 6, 289 (1973).

12) F. Mizutani, Y. Shimura, and K. Tsuda, Chem. Lett., 1984, 199.

13) F. Mizutani, T. Yamanaka, Y. Tanabe, and K. Tsuda, Anal. Chim. Acta, 177, 153 (1985).

14) F. Mizutani and K. Tsuda, Nippon Kagaku Kaishi, 531 (1987) [in Japanese].

15) F. Mizutani, S. Yabuki, and T. Katsura, Anal. Sci., 7, suppl., 871 (1991).

16) F. Mizutani, S. Yabuki, and T. Katsura, Sensors Actuators B, 13-14, 574 (1993).

17) F. Mizutani, Y. Sato, Y. Hirata, T. Sawaguchi, and S.
Yabuki, Sensors Actuators B, 65, 46 (2000).

18) F. Scheller, N. Siegbahn, B. Danielsson, and K. Mosbach, Anal. Chem., 57, 1740 (1985).

19) F. Schubert, D. Kirstein, K. L. Schroeder, and F. Scheller, Anal. Chim. Acta, 169, 391 (1985).

20) F. Schubert, D. Kirstein, F. Scheller, R. Appelqvist, L. Gorton, and G. Johanssen, Anal. Lett., 19, 1273 (1986).

21) U. Wollenberger, F. Schubert, F. Scheller, B. Danielsson, and K. Mosbach, Anal. Lett., 20, 657 (1987).

22) S. Uchiyama, Y. Hasebe, and S. Suzuki, Electroanalysis, 5, 653 (1993).

23) S. Uchiyama, H. Shimizu, and Y. Hasebe, Anal. Chem., 66, 1873 (1994).

24) S. Uchiyama, M. Ono, S. Suzuki, and O. Hamamoto, Anal. Chem., 60, 1835 (1988).

25) S. Uchiyama, S. Maeda, Y. Hasebe, and S. Suzuki, Anal. Chim. Acta, 285, 89 (1994).

26) F. Mizutani and S. Yabuki, Chem. Lett., 1994, 1569.

27) F. Mizutani and S. Yabuki, Sensors Actuators B, 24-25, 750 (1995).

28) A. J. Bard and L. R. Faulkner, Electrochemical Methods. Fundamentals and applications, 2nd ed., Willey, New York, p.474 (2000).

29) K. Aoki, M. Morita, T. Horiuchi, and O. Niwa, Electrochemical Methods Using Microelectrode, The Institute of Electronics, Information and Communication Engineers, Tokyo, p.153 (1998) [in Japanese].

30) O. Niwa, Y. Xu, H. B. Halsall, and W. R. Heinemann, Anal. Chem., 65, 1559 (1993).

31) M. Sakata, K. Matsumoto, N. Obaru, M. Kunitake, H. Mizokami, and C. Hirayama, J. Liq. Cromatogr., 26, 231 (2002).

32) F. Mizutani, S. Yabuki, Y. Sato, and S. Iijima, Bioelectrochemistry, 63, 257 (2004).

33) E. Palecek, M. Tomschik, V. Stankova, and L. Havran, Electroanalysis, 9, 990 (1997).

34) X. Cai, G. Rivas, P. A. M. Farias, H. Shiraishi, J. Wang, M. Fojta, and E. Palecek, Bioelectrochem. Bioenerg., 40, 41 (1996).

35) A. Ori and S. Shinkai, J. Chem. Soc., Chem. Commun., 1995, 1771.

36) D. Kato, S. Iijima, R. Kurita, Y. Sato, J. Jia, S. Yabuki, F. Mizutani, and O. Niwa, Biosens. Bioelectron., 22, 1527 (2007).

37) M. M. Walczac, D. D. Popenoe, R. S. Deinhammer, B. D. Lamp, C. Chung, and M. D. Poter, Langmuir, 7, 2687 
(1991).

38) H. Matsuura, Y. Sato, T. Sawaguchi, and F. Mizutani, Sensors Actuators B., 91, 148 (2003).

39) H. Matsuura, Y. Sato, O. Niwa, and F. Mizutani, Sensors Actuators B., 108, 603 (2005).

40) R. Kurita, Y. Yokota, Y. Sato. F. Mizutani, and O. Niwa, Anal. Chem., 78, 5525 (2006).

41) T. G. Henares, F. Mizutani, and H. Hisamoto, Anal. Chim. Acta, 611, 17 (2008).

42) F. Mizutani, O. Niwa, and R. Kurita, in Practical Bioelectrochemistry - Recent Development in Biosensors and Biofuel Cells (Ed. T. Ikeda), CMC, Tokyo, p.154 (2007) [in Japanese].

43) H. Matsuura, Y. Sato, T. Sawaguchi, and F. Mizutani, Electrochemistry, 71, 411 (2003).

44) H. Matsuura, Y. Sato, S. Yabuki, T. Sawaguchi, and F. Mizutani, IEEJ. Trans. SM, 123, 128 (2003).

45) F. Mizutani, E. Ohta, Y. Mie, and O. Niwa, Chem. Lett., 36, 1148 (2007).

46) M. Vreeke, R. Maidan, and A. Heller, Anal. Chem., 64,
3084 (1992).

47) R. Rajagoplan, A. Aoki, and A. Heller, J. Phys. Chem., 100, 3719 (1996).

48) Y. Iwasaki, T. Horiuchi, and O. Niwa, Anal. Chem., 73, 1595 (2001).

49) Y. Iwasaki, T. Tobita, K. Kurihara, T. Horiuchi, K. Suzuki, and O. Niwa, Biosens. Bioelectron., 17, 783 (2002).

50) F. Mizutani, E. Ohta, Y. Mie, O. Niwa, and T. Yasukawa, to be published.

51) T. G. Henares, M. Takaishi, N. Yoshida, S. Terabe, F. Mizutani, R. Sekizawa, and H. Hisamoto, Anal. Chem., 79, 908 (2007).

52) T. G. Henares, F. Mizutani, R. Sekizawa, and H. Hisamoto, Anal. Sci., 24, 127 (2008).

53) F. Mugele and J.-C. Barnett, J. Phys.: Condens. Matter, 17, R705 (2005).

54) W. Satoh, H. Hosono, and H. Suzuki, Anal. Chem., 77, 6857 (2005).

55) T. Matsue and H. Shiku, Electrochemistry, 74, 107 (2006). 